\title{
Historia de la Antropología en España: Textos clásicos y aportaciones nacionales
}

La escasa importancia de la antropología en nuestro país ha impedido que aparecieran manuales de historia de la disciplina escritos por españoles hasta finales de los años setenta. Este hecho no ha sido obstáculo para que surgieran algunas aportaciones aisladas, honrosas excepciones que no constituyen materia suficiente como para que nuestra afirmación anterior resulte errónea. Tras el paréntesis de la guerra civil, los esfuerzos de algunos autores a finales de los sesenta y comienzos de los setenta significaron el primer impulso que recibía la historia de la antropología por parte de personas radicadas en España, después de años de ostracismo. Si nos remontamos a estos trabajos pioneros puede establecerse una continuidad de poco más de dos décadas en la tarea de historiar la antropología, pero ello supone un recurso engañoso. No ha habido una historia de la antropología hecha por españoles capaz de hacer frente a las traducciones foráneas. En la práctica, el dominio de los manuales extranjeros ha sido un hecho común. Como además estos manuales se aceptaban sin una base crítica que desvelara sus raíces metodológicas, nacionalistas y de escuela, se ha producido la paradoja de que hemos aprendido antropología a través de manuales cargados de supuestos que nos eran ajenos. Hemos sabido del valor de movimientos antropológicos ingleses, franceses y estadounidenses antes de poseer una antropología con una base institucional firme, lo cual ha propiciado la adopción de puntos de vista extraños a nuestras peculiaridades. Asimismo, al conceder primacía a otras tradiciones historiográficas no sólo hemos perjudicado el desarrollo de la española, sino que, por comparar entre sí momentos distintos de la evolución de ésta y aquéllas, nos hemos visto obligados a dar por supuesta su debilidad.

Es importante distinguir los tres problemas que se desprenden de lo anterior: por una parte, ha resultado dañada la investigación de nuestra propia historia de la antropología (la de los antropólogos españoles); de otra, el detrimento ha sido para la historia de la antropología general que pueden hacer los historiadores españoles. Por último, la historiografía española de esta especialidad ha tenido que hacer frente a otras que poseían tras de sí una tradición de estudios mucho más rica. Ninguna de estas opciones es baladí. Si no vinculamos la antropología con una tradición nacional su acep- 
tación social siempre será menor; el reconocimiento de ancestros propios es el camino que históricamente han recorrido las distintas disciplinas para su mejor institucionalización. A la vez, si los historiadores locales no afrontan la realización de una historia (general) de la antropología desde sus propios presupuestos, es difícil que se logre descargar a ésta de las adherencias foráneas no siempre manifiestas en las que se apoya. En ambos casos, lo que se ha de estudiar no es algo objetivo, sino que su conocimiento está determinado en gran parte por el interés con que los historiadores afronten su tarea. La historia de la antropología depende tanto de los hombres y materiales que estudia como de la capacidad que demuestren sus practicantes para vincular aquéllos a su historia, o, lo que es lo mismo, tanta importancia tiene el objeto estudiado como los estudiosos. Por tanto, si queremos desarrollar la historia de la antropología no queda otra opción que trabajar sobre ella.

Las pruebas demuestran que el empeño por parte de los historiadores ha sido constante. En el transcurso de dos décadas la distancia recorrida ha sido enorme, hasta el punto de publicarse ahora en un año lo que en ocasiones exigió un lustro. Sin embargo, y esto afecta a la posibilidad misma de una historiografía española de la antropología, la presencia de manuales españoles en el mercado no ha servido para sustituir a los que proceden del exterior. Para averiguar la causa de ello tal vez sea útil analizar algunas aportaciones españolas a la historia de la antropología. Como ésta es una disciplina de carácter comparativo, sin duda la manera más adecuada de acercarse a tales textos será poniéndolos en parangón con obras de autores extranjeros cuya divulgación en castellano ha convertido en clásicas.

Sin discusión, este calificativo le es aplicable mejor que a ninguna otra obra a la Historia de la etnología de Lowie ${ }^{1}$. Durante treinta años ha sido considerado la máxima autoridad en la materia; posiblemente este dato pueda ser utilizado por algunos autores como un reproche, mas, al margen de la evolución de la teoría antropológica desde la fecha de su publicación, que obviamente no puede exponer, se trata de un libro valioso. Algunos de sus defectos nos pueden permitir entender mejor el progreso en la forma de analizar la historia de la antropología. Lowie realiza un enorme esfuerzo por unificar la tradición antropológica de su época. Su interés por presentar los estudios etnológicos de una orilla y otra del Atlántico unidos por intereses comunes no es un síntoma de objetividad. Muy al contrario, Lowie ofrece un sacrificio en pro de la institucionalización de la antropología: presentarla con un carácter internacional es la mejor garantía para que se apoye su desarrollo en cada país. El autor, no obstante, no renuncia a ninguno de los

1 (México: F.C.E., 1981) (1937). 
principios que su pertenencia a la escuela boasiana le hace compartir. Así, su actitud crítica hacia aquellos autores que hacen de la búsqueda de leyes un objetivo de la ciencia social, debe señalarse como una postura teórica que en absoluto comparten la mayor parte de los antropólogos. El mismo énfasis puesto en las páginas finales a favor de una antropología basada en «la manera universalista y a la vez objetiva con que Tylor y Boas enfocaron sus problemas», no deja de ser, a la par que un deseo insatisfecho, una declaración de su propia tendencia metodológica. En el aspecto formal, la Historia de la etnología presenta muchos de los elementos criticados por los historiadores de la ciencia actuales. Las polémicas sobre el origen de la antropología adquieren en el libro de Lowie el aspecto de una elección arbitraria. Su opción entre el hombre y su obra aparece claramente dibujada: muestra un esbozo biográfico de cada autor previo a la explicación de su aportación teórica, como si ambos carecieran de relación. En definitiva, se podría afirmar que la historiografía tradicional encuentra en la obra de Lowie su mejor ejemplo en lo que a la antropología se refiere: su autor es practicante de la propia disciplina y sus intenciones pedagógicas son evidentes.

Si la valoración de cualquier libro es siempre difícil, hacer justicia al de Marvin Harris ${ }^{2}$ se convierte en un trabajo imposible. Se trata de una obra que provoca los más variados comentarios, desde la descalificación al entusiasmo y desde el gesto desdeñoso a la atracción sin barreras. Pocos son los lectores indiferentes ante el trabajo de Harris. Pero se puede afirmar que un buen número de estudiantes se han sentido atraídos hacia la antropología gracias a la exposición de la teoría antropológica que el norteamericano ha realizado. Sus libros, no sólo éste, son una fuente apasionada y apasionante de información, expuesta con un estilo literario brillante y atractivo; tal vez por ello rebasa con facilidad los límites estrictamente antropológicos ${ }^{3}$. La simpatía que despiertan sus páginas hacia el contenido que allí se expresa no evita que éste resulte a veces inexacto. Harris expone su punto de vista, y se sirve del pasado en beneficio de su opción metodológica presente. Ciertamente, en la fecha de su primera edición -1968-, esta opción estaba en inferioridad de condiciones respecto a sus competidores, lo que no ocurre en la actualidad, por lo que la «comprensión» de la que pudiera gozar la edición original, carece ahora de razón de ser.

2 M. HARRIS, El desarrollo de la teoría antropológica. Una bistoria de las teorías de la cultura (Madrid: Siglo XXI, 1978) (1968).

3 G. BuENo, «Determinismo cultural y materialismo histórico», El Basilisco, 4 (1978), pp. 4-28; D. Alvargonzález Rodrfguez, Ciencia y materialismo cultural (Madrid: UNED, 1989). 
El presentismo -estudio del pasado en beneficio del presente- en el que va envuelta la exposición hay que tenerlo en cuenta. La investigación se subordina a los intereses del momento, y la visión general se simplifica en favor de la polémica actual. Los capítulos tienden a reproducir no tanto lo que fue, como los deseos de su autor: la Ilustración que Harris nos presenta es irreal, alejada de su contexto histórico y vacía de los contenidos que amenazan con romper el molde previamente establecido. Locke es considerado el artífice de una aportación más que discutible. Los ilustrados alemanes apenas reciben atención, acaso porque lo que interesa son los esbozos de teoría materialista que pudieran existir en el siglo XVIII, y éstos se encuentran mejor representados entre ingleses y franceses. Algunas teorías, como la del progreso, reciben un trato contradictorio, aceptándose y negándose su existencia en la Ilustración sucesivamente. Defender que el origen de la antropología tuvo lugar entre los ilustrados exige no sólo mayor argumentación que la proporcionada por Harris, sino también, el manejo de fuentes directas, lo que no es el caso.

Es un mérito del autor defender la existencia de un evolucionismo social anterior al auge del evolucionismo biológico darwinista, pues no siempre parece aceptarse la precedencia de las teorías sociales con respecto a las correspondientes teorías científicas ${ }^{4}$. Sin embargo, la visión dualista de los teóricos del siglo XIX (materialistas-idealistas, liberales-reaccionarios, cientificistas-oscurantistas, etc.), parece en extremo simplificadora: el panorama es mucho más complejo y lleno de eclecticismo ${ }^{5}$. Cuando trata de la antropología norteamericana, Harris muestra un conocimiento detallado de los datos y de lo que había tras ellos, pero su visión es parcial; estamos ante la información de un insider, pero el manejo de la misma es más propio de un outsider, lo que en absoluto ocurre al tratar el estructuralismo francés y a la antropología social británica. No sólo el espacio dedicado a estas escuelas resulta muy inferior a lo que su importancia parece exigir, sino que la misma manera de hacerlo permite convertir estos dos capítulos en el material de preferencia a la hora de criticar esta obra.

Por último, dos cuestiones centrales: la evaluación de Marx, problema que tanto aflige a algunos historiadores hispanos, y la coherencia de una

4 Véase E. Ronzón, Antropología y antropologías. Ideas para una bistoria crítica de la antropología española. El siglo XIX (Oviedo: Pentalfa Ediciones, 1991), pp. 74 y 84. La autora no parece admitir la posibilidad de un evolucionismo de carácter social previo al darwinismo.

5 G. W. STOCKING, «Tylor, Edward Burnett», Enciclopedia Internacional de las Ciencias Sociales, 10 (1974 [1968]), pp. 543-549; «"Cultural Darwinism" and "Philosophical Idealism" in E. B. Tylor: A Special Plea for Historicism in the History of Anthropology", Soutbwestern Journal of Antropology, 21 (1965), pp. 130-147. 
historia de este calibre respecto a la teoría antropológica que su autor defiende. Un capítulo dedicado a las aportaciones antropológicas de Marx y Engels y las continuas menciones de ambos a lo largo del libro no parecen estar en consonancia con el papel desempeñado por ambos en antropología. Para justificar su importancia Harris necesitaría demostrar con datos concretos y no con afirmaciones rotundas, que la antropología cultural «se desarrolló enteramente como una reacción contra él [el marxismo]», pero en su obra no hay pruebas de ello. De otra parte, la historia que Harris nos ofrece es el mejor manifiesto que puede esgrimir el materialismo cultural como foco de atracción. Su sencillez de expresión, claridad de explicación, amplitud y buen estilo, la convierten en un arma formidable para atraer nuevos adeptos. Mas, desde un punto de vista teórico, El desarrollo de la teoría antropológica, no es una historia escrita de acuerdo con los principios que su autor defiende. Hacer una historia objetiva y conforme al punto de vista del observador es algo que se contradice con una historia presentista cargada de ideología. La historia de Harris corre el riesgo de olvidar lo que ha sido la antropología para fabricar lo que, a su juicio, debería ser.

La Historia de la antropología de P. Mercier es una de las primeras obras de esta temática traducidas al castellano ${ }^{6}$. Su origen francés no es obstáculo para que el autor haga un uso abundante de la historia de Lowie, a quien cita o tiene en cuenta para afirmar o disentir continuamente. En la medida en que su publicación original se realiza treinta años después de la de Lowie, el autor se ve obligado a una actualización de los problemas y tendencias de la etnología cuya originalidad no debe serle negada. Esta misma diferencia en los años de publicación de ambas obras, permite a Mercier un tratamiento mucho más al día de la historia de la antropología, aunque sigue sin existir una presentación del contexto de cada autor o época. La constante alusión a los clásicos franceses y a las oportunidades perdidas de la antropología francesa convierten en injusto el reproche que hace a Lowie por su énfasis en lo norteamericano; en ambos es evidente la glorificación de la tradición propia.

La prehistoria de la disciplina que Mercier dibuja no va más allá de la mera relación de nombres. A veces, como en el caso de Aristóteles o del Inca Garcilaso, exagera o desconoce, muy en la línea de artículos de fundadores. No obstante, debe admitirse que la mera consideración de un capítulo dedicado a estos autores merece ser alabada por la novedad que suponía en la época en que se realizó. Mercier, sin embargo, no presta atención a los numerosos artículos de carácter historiográfico publicados hasta ese momento, lo que repercute desfavorablemente en la riqueza bibliográfica e informativa

\footnotetext{
6 P. MERcier, Historia de la antropología (Barcelona: Península, 1969) (1966).
} 
de su obra; este mismo hecho se repite al dejar de lado numerosos datos biográficos que aparecen en la historia de Lowie. Estamos, en definitiva, ante una aceptable historia, que en el ámbito francés se muestra superior a las de Poirier ${ }^{7}$, publicadas con posterioridad, pero en las que se advierte el paso del tiempo más de lo deseable.

El libro de Michèle Duchet, Antropología e bistoria en el siglo de las luces ${ }^{8}$, constituye un excelente ejemplo de cómo conjugar la historia de las ideas en una época determinada con la historia de la antropología. A la vez, es una valiosa guía para aquellos autores deseosos de estudiar su propia tradición nacional desde un punto de vista antropológico, sin necesidad de ocuparse únicamente de los siglos XIX y XX. La abundante bibliografía de la primera parte del libro encaja perfectamente dentro de la historia de las exploraciones. La literatura de viajes y su difusión en Francia se erige en objeto de estudio, un tema, por lo demás, al que la autora se ha dedicado durante muchos años. Algunas atribuciones son discutibles, pero tanto el cúmulo de datos manejado, como la amplitud del tema, permiten comprender las dudas sobre la autoría de un relato de viajes. La segunda parte del libro es la que constituye una auténtica aportación a la historiografía de la antropología. El análisis pormenorizado del pensamiento de Buffon, Voltaire, Rousseau, Helvecio y Diderot, adquiere un valor notable cuando se compara con los clásicos artículos de fundadores y padres de la antropología, tan propios de la historiografía tradicional. Duchet intenta romper algunos de los mitos existentes sobre la Ilustración, como su anticolonialismo. La presentación interna del pensamiento de los ilustrados y el interés por la lógica de su discurso permiten a la autora mostrar las influencias que sobre aquéllos ejercieron las crónicas de viajes y las relaciones de exploradores y misioneros. De esta forma quedan unidas las dos partes de la obra y se valora mejor el esfuerzo inicial. Es de destacar el conocimiento que Duchet demuestra de las fuentes españolas frente a los errores frecuentes en otras historias de la antropología francesa ?. Todo ello hace de su libro un interesante estudio del pensamiento ilustrado francés en relación con la antropología.

7 J. POIRIER, «Histoire de la pensé ethnologique», Ethnologie Generale (Paris: Gallimard. Encyclopedie de la Pleiade, 1968), pp. 3-125; Histoire de l'ethnologie (Paris: P.U.F., 1969) (Trad. esp. México: F.C.E., 1987).

8 (México: Siglo XXI, 1975) (1971).

9 Puede apreciarse en las obras de Mercier y Poirier ya citadas, pero la tradición se mantiene en B. RupP-EISENREICH, Histoires de l'anthropologie (XVI-XIX siècles) (Paris: Klincksieck, 1984) (Trad. esp. Madrid: Júcar, 1989). En el artículo de S. Auroux («Linguistique et anthropologie en France -1600-1900-») se afirma que Pedro Mártir 
Michel Panoff ha intentado recoger lo mucho que la antropología debe a Malinowski en su obra Malinowski y la antropologia ${ }^{10}$. Su estudio consiste en una defensa a ultranza de la importancia de la obra del antropólogo polaco. Los dos primeros capítulos se dedican al hombre y su época en un tono tradicional: una breve biografía y las influencias del joven Malinowski, al margen de los motivos que pudieron impulsarlo a aceptarlas. A continuación se estudia la obra de Malinowski mediante un tratamiento diacrónico que elude la profundización. La parte final del libro es una selección de textos extraídos de las obras del biografiado, a la que acompaña una bibliografía no muy completa. La amenidad que Panoff intenta dar a su relato se pierde inevitablemente ante el cúmulo de críticas que el antropólogo francés prodiga. Los discípulos, los compañeros, la misma viuda de Malinowski, son objeto de sus ataques. La publicación del Diario de Malinowski constituye una excelente piedra de toque para apreciar hasta qué punto está el autor incapacitado para comprender la importancia que puede tener en la historia de la antropología. La admiración mal entendida de Panoff por Malinowski se erige en el principal escollo para su justa valoración.

Muy distinto es el libro de Jean Duvignaud, El lenguaje perdido. Ensayo sobre la diferencia antropológica ${ }^{11}$. El autor no presenta un ensayo de investigación histórica al estilo corriente entre los antropólogos, pero los estudiosos de la historia de la antropología pueden encontrar en él una buena fuente alternativa sobre alguno de los autores que estudia ${ }^{12}$. Elabora una investigación sobre Morgan, Lévy-Bruhl, Frobenius, Malinowski y LéviStrausss, desde una óptica peculiar: para Duvignaud, el lenguaje perdido constituye la materia que sirve de objeto a la antropología. No hace falta decir que el lenguaje perdido es propio de los grupos reducidos al silencio, característica que comparten los pueblos salvajes y los proletarios. Duvignaud

viajaba con Colón (p. 294), cuando es conocido que el humanista italiano jamás se embarcó para América; por otra parte, tras citar la Historia natural y moral de las Indias (México: F.C.E., 1979) del P. Acosta (ibidem, p. 295), se afirma que «la larga discusión sobre el origen del poblamiento americano» comenzó con «Grotius (1642)» (ibidem, p. 296), cuando en el libro de Acosta citado, publicado en 1590, se defiende la hipótesis acerca del poblamiento americano "por camino de tierra» dado que «en efecto debe continuarse el un orbe con el otro»(ACostA, op. cit., p. 59), hipótesis que ya fue citada por Tylor en 1884 .

10 (Barcelona: Labor, 1974) (1972).

11 (México: Siglo XXI, 1975) (1973).

12 Sin querer caer en el riesgo de la «precursitis», creo que esta obra admite un digno paralelismo con el libro tan de moda de C. GEERTZ, El antropólogo como autor (Barcelona: Paidós, 1989), y que éste puede extenderse tanto a sus contenidos como a la misma estructura de la obra. 
se aproxima a sus autores con afecto, en una postura de simpatía que le lleva a intentar su comprensión. No obstante, no cae en el exceso. Su libro no disculpa los errores cuando los ha habido, aunque intenta situarlos en la coordenada que los explique. Por eso es capaz de apreciar en su exacto valor la función del Diario malinowskiano como vínculo o sustitutivo de la lejana sociedad blanca, algo que se le escapaba a Panoff. El mismo reconocimiento del trabajo de campo de Cushing, Boas o Codringtron, evitan a Duvignaud el papel de mitificador de la labor de Malinowski que otros adoptan. Ante esta obra sólo cabe lamentar que su autor se ocupe únicamente de los salvajes y deje de lado la segunda parte de sus silenciados; hacer caso omiso de los proletarios después de haber establecido una comparación tan fértil no deja de ser una manera de desperdiciar un argumento prometedor.

Las traducciones al castellano de obras inglesas tienen en el libro de Adam Kuper, Antropología y antropólogos. La escuela británica: 1922$1972^{13}$, una excelente justificación. Se trata de un trabajo que estudia el funcionalismo británico desde sus orígenes, sitúa a sus protagonistas en su contexto y los contempla con ojos desmitificadores. Kuper logra aproximarse a la historia de la antropología británica recreándose en el ambiente formativo de sus figuras principales, valorando sus influencias teóricas y el motivo de éstas. Los dos primeros capítulos de la obra, dedicados a Malinowski y Radcliffe-Brown son una excelente introducción histórica; en el resto de los capítulos históricos la obra decae algo, tal vez por la dificultad de valorar lo que estaba tan próximo al escribirse el libro. El estudio de las relaciones entre colonialismo y antropología no carece de interés, sobre todo para los que siguen creyendo que la etnología es un producto del primero. El apéndice sobre universidades inglesas y el estudio de la antropología social, y la guía de autores y obras que acompañan la edición española resultan útiles por su valor informativo.

Si Kuper quería estudiar la antropología social británica tenía buenos motivos para comenzar con Malinowski y Radcliffe-Brown. Se puede aceptar la coherencia del conjunto elegido sin echar en falta ningún nombre ilustre. Pero estudiar una época no significa ignorar el resto, y es posible que la antropología social no se entienda completamente sin el fondo de personajes como Tylor, Frazer, Rivers, etc. Por otra parte, el libro de Kuper parece el producto lógico de una mirada incapaz de optar por una visión desde fuera o desde dentro. Kuper conoce la historia de la antropología social británica desde dentro porque se ha formado en ella; su parentesco con anteriores generaciones de antropólogos formados en la misma línea supone,

13 (Barcelona: Anagrama, 1973). 
asimismo, una fuente inapreciable de información. Mas, también parece empeñado en hacer una historia desde una óptica externa, porque sólo de esa forma puede unificar como la tradición de una escuela lo que desde el punto de vista de sus integrantes son grandes desavenencias. Al elegir una línea intermedia entre ambas opciones, Kuper obtiene algunas ventajas, pero también problemas. Entre las primeras están la unidad cronológica y lógica que posee el texto: se estructura en generaciones de entreguerras, postguerra y años setenta, y se estudian los trabajos de cada autor a partir de su biografía. Entre los problemas se podría señalar que seguimos desconociendo cuál es el sentir de la antropología británica ante la antropología de sus colegas norteamericanos, pues la famosa polémica Murdock-Firth trataba más bien el sentir de los norteamericanos hacia aquéllos.

El libro de Ronald L. Meek, Los orígenes de la ciencia social. El desarrollo de la teoría de los cuatro estadios ${ }^{14}$, constituye un buen estudio del desarrollo de dicha teoría desde sus orígenes, que sitúa en la Ilustración francesa y escocesa, hasta 1800 . Dedica, además, un primer capítulo a la prebistoria de dicha idea, donde se analizan autores que vivieron entre la antigüedad clásica y 1750. La información que proporciona el libro de Meek sobre el pensamiento ilustrado y sus influencias posteriores es valiosa y profunda. Se aprecia, no obstante, un excesivo énfasis en los aspectos económicos de este pensamiento, lo que va en detrimento de otras tendencias intelectuales propias de la época. De hecho, no se pueden dejar de plantear preguntas como las que siguen cuando se leen los libros de Meek: ¿la teoría de los cuatro estadios es la única que ha influido en los pensadores del siglo XIX? ¿Es la principal línea de pensamiento de acuerdo con el posterior desarrollo de las ciencias sociales? ¿Era la principal preocupación de los ilustrados? La obra de Meek, aunque valiosa para investigar la historia de una corriente de investigación en ciencias sociales, parece guardar más relación con la historia del pensamiento económico - especialidad de la que no en vano es profesor Meek y sobre la que ha publicado diversos artículos ${ }^{15}$ que con la antropología; tomarla en un sentido excluyente respecto de otras tradiciones históricas en ciencias sociales, como se ha hecho en España, puede ser un grave error.

Las traducciones de manuales norteamericanos, franceses e ingleses encuentran un contrapunto de interés en la obra de Annemarie de Waal Ma-

14 (Madrid: Siglo XXI, 1981) (1976).

15 Una traducción de éstos al castellano en R. L. MEEK, Smith, Marx y después. Diez ensayos sobre el desarrollo del pensamiento económico (Madrid: Siglo XXI, 1980) (1977). 
lefijt ${ }^{16}$. Su novedad consiste en que su autora es una mujer y su país de origen es Holanda, sin embargo, la publicación original se hizo en inglés y la autora es una antropóloga que ha hecho trabajo de campo en Surinam, con lo que se confirma una vez más la escasez de traducciones de historiadores de la antropología, en el pleno sentido del término, que existen en nuestro idioma. Por lo demás, la historia que Waal Malefijt presenta resulta ambiciosa, y de esa ambición pueden venir algunos de sus defectos. Sitúa el origen de su historia entre los griegos, pero recurrir a los mitos helenos en un breve esbozo y continuar con Tales de Mileto, exige una justificación que la autora no proporciona. Confundir la historia de la antropología con la historia de la filosofía es un recurso que garantiza un amplio abanico de autores y una bibliografía abundante, pero se corre el riesgo de desnaturalizar la historia resultante. Esto es lo que ocurre con la obra que comentamos: buena parte del esfuerzo hubiera sido más fructífero de explicarnos su causa o, simplemente, si se hubiera suprimido. En realidad, la misma Waal Malefijt reconoce en algunos autores sus puntos de vista «antiantropológicos» y según avanza su historia sugiere algunos criterios que, debidamente ordenados, podrían apoyar el origen de la antropología en los siglos XVI, XVIII o XIX. Alejándose de sus primeras páginas, el libro gana en dominio de los datos y consigue una exposición de los autores que cita superior a la de otros textos similares. La autora ha sabido aprovechar las historias de la antropología más conocidas, y un apreciable número de recopilaciones sobre el progreso, el evolucionismo, darwinismo, etc. A su favor cabe decir que el capítulo dedicado a la antropología y el concepto de raza no cae en los tópicos de otras historias: estudia el problema otorgando continuidad a los siglos XIX y XX, e identifica como antropológicas las polémicas de este último, al margen de la especialidad del que las provoca.

En historia de la antropología las traducciones de autores extranjeros compiten con una producción nacional cada vez más en auge. La búsqueda de los propios orígenes es un foco de atracción que apoya la dedicación a la historia de la antropología. Desde luego, no podemos dejar a un lado la base política de este auge: la configuración autonómica de nuestro país convierte en objetivo institucional la búsqueda de la propia tradición. Dentro de esta última, la investigación de las formas peculiares de vida de cada región resulta prioritaria. A la labor llevada a cabo por eruditos y folkloristas añade la antropología su carácter científico, lo que la convierte en el instrumento ideal para estos fines. Sin embargo, como no todos los estudios se centran en la historia de la antropología española, justo es reco-

16 Imágenes del hombre. Historia del pensamiento antropológico (Buenos Aires: Amorrortu editores, 1983) (1974). 
nocer que el interés no es sólo producto de la exigencia política. La mejor demostración de la expansión que experimenta este campo en nuestro país se encuentra no sólo en las cada vez más numerosas publicaciones específicas, sino también en los conocidos Boletines de bistoria de la antropología ${ }^{17}$ que vienen sucediéndose desde hace algún tiempo, y en el papel que ocupa la especialidad en los Congresos de Antropología de nuestro país. Un análisis de algunas de esas aportaciones puede ayudar a aclarar en qué nivel se encuentra la historia de la antropología que aquí se hace en relación a la de fuera de nuestras fronteras.

Uno de los estudios más citados por los historiadores de la antropología española posiblemente sea «Una gran encuesta de 1901-1902 (Notas para la Historia de la Antropología Social en España)» ${ }^{18}$. Este ensayo fue, en su momento, de consulta obligada para todo aquel que quisiera acercarse a la historia de la antropología española; con posterioridad sigue siendo una buena introducción, pero han salido a la luz estudios sobre algunos de los autores y temas tratados por el profesor Lisón, que matizan y desarrollan las afirmaciones iniciales. También parece necesitado de una mayor discusión sobre los fundamentos de la fecha de origen elegida, pues, contra lo que indica su autor, ésta no es «marcadamente lábil» ${ }^{19}$. No puede menos de contrastarse la atención que ha merecido este artículo con la suerte corrida por el que le acompañaba, como capítulo 1, en Antropología social en España: «Pequeña historia del nacimiento de una disciplina» ${ }^{20}$ no parece haber merecido gran atención por parte de sus lectores. Carecemos de una valoración antropológica adecuada de nuestros siglos XVI y XVII, tarea que sólo han afrontado un reducido número de autores dentro y fuera de

17 Boletín de Historia de la Antropología. Laboratorio de Antropología Social, Departamento de Prehistoria, Antropología y Paleoambiente. Universidad de La Laguna (Canarias): 1 (1988), 2 (1989) y 3 (1990).

18 C. Lisón TolosanA, «Una gran encuesta de 1901-1902 (Notas para la historia de la Antropología Social en España)», Antropología Social en España (Madrid: Akal, 1977) (1968), pp. 105-179.

19 Es curiosa la coincidencia a la hora de no apreciar problema alguno en la elección del comienzo de la historia de la antropología entre el ensayo que «inaugura» los estudios de historia de la antropología española en su etapa más reciente, y el texto de esta disciplina que ha disfrutado de mayor autoridad hasta los años sesenta: «Cualquier punto de partida resulta arbitrario. Empezaremos por Meiners y Klemm, porque los dos tuvieron un concepto bastante claro de lo que es el tema medular de la etnografía» (LowIE, op. cit., p. 21).

20 C. Lisón Tolosana, «Pequeña historia del nacimiento de una disciplina», $A n$ tropología Social en España (Madrid: Akal, 1977) (1971), pp. 9-104. 
nuestro país ${ }^{21}$. Sorprende todavía más, por ello, el silencio sobre este artículo, y, sobre todo, asombra que sus conclusiones, negando el nacimiento de la antropología en la literatura de los escritores de Indias, pero admitiendo su labor etnográfica, no hayan sido objeto de discusión. Sin duda, a veinte años de su publicación, aquellas afirmaciones no pueden sostenerse, y estamos en condiciones de comprender que eran más bien fruto de la situación precaria que sufría en aquel entonces la antropología española.

El profesor Palerm recopiló una serie de textos que editó bajo el título de Historia de la Etnología; de los tres volúmenes originales, dos, a los que aludimos, han sido reeditados con correcciones en nuestro país ${ }^{22}$. Estos últimos corresponden a lecturas seleccionadas de distintos autores, de $\mathrm{He}$ ródoto a Morgan. Palerm hace una introducción a cada uno de los volúmenes y un comentario previo a cada texto elegido. La introducción al primer volumen nos da a conocer las circunstancias en las que surgió la obra, y recoge la idea de Palerm según la cual la historia de la etnología es, junto con el trabajo de campo, fundamental para el antropólogo. También aquí la crítica hacia otras historias de la antropología forma parte del patrimonio que la nueva obra lleva consigo, y Palerm no olvida señalar a algunos de sus predecesores: Lowie, Penniman, Hodgen, Slotkin, Hallowell, Harris, y los textos comentados de Manners. En clara referencia al problema planteado por la historia de Harris, la introducción al volumen segundo justifica la ausencia de Marx por dos causas: 1) habría que discutir su relación con la antropología y el evolucionismo de manera más extensa que lo per-

21 Algunos trabajos que se han ocupado de ello en los últimos años: A. PAGDEN, The Fall of Natural Man. The American Indian and the Origins of the Comparative Ethnology (Cambridge University Press, 1982) (Trad. esp. ampliada, Madrid: Alianza editorial, 1988); J. BESTARD y J. CONTRERAS, Bárbaros, paganos, salvajes y primitivos. Una introducción a la Antropología (Barcelona: Barcanova, 1987) y los artículos de F. del PINO, que ya dedicara su tesis doctoral al tema: «Los cronistas de las culturas indígenas de América: su valor antropológico», A. JIMÉNEZ (ed.), I Reunión de Antropólogos Españoles (Sevilla: Universidad de Sevilla, 1975), pp. 107-125; «Contribución del P. Acosta a la constitución de la etnología. Su evolucionismo», Revista de Indias, 153-154 (1978), pp. 507-46; «Los reinos de Méjico y Cuzco en la obra del P. Acosta», J. AlCina Franch (ed.), Economía y sociedad en los Andes y Mesoamérica (Madrid: Univ. Complutense, 1979), pp. 13-43; "Culturas clásicas y americanas en la obra del P. Acosta», F. de Solano y F. del PINO (eds.), América y la España del siglo XVI (Madrid: CSIC, 1982), vol. I, pp. 327-362.

22 A. PALERM, Historia de la etnología, I: los precursores (México, D.F.: INAHCIS-SepInah, 1974) (2." ed. corregida, Madrid: Alhambra, 1982); Historia de la etnología, II: los evolucionistas (México, D.F.: INAH-CIS-SepInah, 1976) (2." ed. corregida, Madrid: Alhambra, 1982); Historia de la etnología, III; Tylor y los profesionales (México, D.F.: INAH-CIS-Ediciones Casa Chata, 1977). 
mitido en ese volumen, y 2) la influencia de Marx en antropología se hizo notar en la segunda mitad del siglo XX, no en el XIX.

Las introducciones a los textos seleccionados son breves, valorando en esbozo la contribución antropológica del autor y los motivos que le llevaron a realizar ésta. En el segundo volumen aumentan algo los preámbulos y se citan los libros de los que proceden los textos, no sólo el título de la obra del autor seleccionado. Se incluye, además, a modo de bibliografía, algún libro útil sobre el autor. No está de más destacar que Palerm introduce en su antología un texto de Costa, opción novedosa, acorde con la preocupación por la historia de la antropología española que ya demostrara con su ponencia al I Congreso Español de Antropología ${ }^{23}$. El problema más importante que plantea la obra de Palerm tal vez sea su pretendida utilidad pedagógica. Al curioso que se acerque a la antropología a través de esta Historia no se le facilita criterio alguno para distinguir con precisión qué sea ésta. La selección de autores llevada a cabo por Palerm no permite distinguir a auténticos etnólogos de los que sólo lo son por una minúscula aportación. La misma brevedad de las introducciones a cada autor mutila en gran parte la posibilidad de un correcto entendimiento.

Los problemas de historia de la antropología en los que ha trabajado Josep R. Llobera, le vinculan más con Inglaterra, donde se ha formado y en cuyas universidades ejerce su trabajo, que con España. Sin embargo, tanto su origen catalán como sus frecuentes publicaciones en castellano nos permiten hablar de una obra que en absoluto puede considerarse carente de interés ${ }^{24}$. Su libro Hacia una bistoria de las ciencias sociales es una recopilación de diversos artículos y materiales de su tesis doctoral inglesa. En él se tratan algunos de los problemas con los que se enfrenta la historia de la antropología a partir de una perspectiva epistemológica althusseriana.

23 «Sobre los antropólogos españoles de México desde el exilio de 1939», Actas del I Congreso Español de Antropología (Barcelona: Universidad de Barcelona, 1980), vol. II, pp. 173-184.

24 En castellano, Llobera se había acercado a la historia de la antropología con su post-scriptum «Algunas tesis provisionales sobre la naturaleza de la antropología», incluido en su compilación La antropología como ciencia (Barcelona: Anagrama, 1975), pp. 373-387. Esta visión se caracterizaba por concebir la antropología como una ciencia determinada por su contexto colonial, y aceptar una metodología ecléctica, mezcla de marxismo, falsacionismo y algunas dosis de paradigmatismo kuhniano. Con posterioridad, Llobera modifica su postura en la ponencia presentada al I Congreso Español de Antropología: "Algunos problemas epistemológicos de la historia de la Antropología», Actas del I Congreso Español de Antropología (Barcelona: Universidad de Barcelona, 1980), vol. II, pp. 73-85, adelanto de lo que ofrece su tesis doctoral inglesa y su libro, J. R. LLOBERA, Hacia una historia de las ciencias sociales. El caso del materialismo bistórico (Barcelona: Anagrama, 1980). 
El resto del libro se compone de varios análisis sobre el impacto de la obra de Marx en los científicos sociales (Weber, Durkheim y sus seguidores, etc.), y sobre la propia valoración de la obra de éste desde el punto de vista de la antropología (sus escritos sobre las sociedades precapitalistas, Wittfogel, su crítica de Marx y el modo de producción asiático, y la influencia del marxismo en la antropología francesa). Esta última preocupación, que, como en Palerm, se vincula claramente a la ya expresada por Harris, según la cual la antropología se desarrolló como una reacción contra el marxismo, es más interesante, si cabe, en un país como el nuestro, donde históricamente no ha habido teóricos marxistas de talla internacional. Tal vez por ello cabe disculpar a Llobera cuando afirma que «es un hecho indiscutible que ni Marx ni sus teorías aparecen citados en las historias de la antropología antes de 1968» ${ }^{25}$. Su extensa cita de las historias que ha estudiado en relación a ese asunto nos hace pensar en una opinión fundamentada, pero basta mirar el capítulo que Lowie, al que también incluye en su visión negativa, dedica a Morgan en su historia para deshacer esta afirmación: Marx y Engels son citados para explicar a qué se debe la fama del estudioso de los iroqueses ${ }^{26}$. Este detalle desafortunado no es, sin embargo, el único a destacar. Llobera utiliza como un logro indiscutible las obras del ya citado R. L. Meek, y extrae buena parte de sus conclusiones acerca de los orígenes de la antropología a partir de los textos de éste. Pero, como hemos apuntado anteriormente, nada garantiza que las ciencias sociales hayan tenido una única fuente de desarrollo y, en cambio, existen bastantes indicios en contra de tal suposición. Incluso, si utilizáramos el mismo criterio que Llobera emplea para defender los «inicios de la antropología» en la Ilustración, nos veríamos obligados a dar de baja como antropólogos a algunos de los más famosos practicantes de la disciplina ${ }^{27}$. Tanto esta pos-

25 J. R. Llobera, Hacia una bistoria de las ciencias sociales..., p. 20.

26 R. H. LOWIE, op. cit., pp. 72-73.

27 Para Llobera (Hacia una bistoria de las ciencias sociales..., p. 61) «existen varias razones que me inducen a pensar que la Ilustración fue el momento en que se establecen los fundamentos de una ciencia del hombre y de la sociedad: 1. El intento de formular leyes del hombre y de la sociedad; leyes formuladas en términos de causa y efecto. 2. La idea de que hay leyes invariables de la naturaleza humana y leyes cambiantes de la sociedad. 3. La formulación de un concepto de totalidad social como un todo social consistente en un número de niveles interrelacionados, donde el determinante es el económico. 4. La formulación de la idea de que la historia se puede explicar óptimamente como una sucesión de totalidades sociales, siendo la evolución de un estadio a otro el producto de cambios habidos en el nivel económico».

Estas condiciones, sin embargo, no han formado parte de las creencias de numerosos antropólogos; basta recordar que Boas y su escuela, con Lowie a la cabeza, no aceptaron el determinismo económico ni la existencia de leyes socioculturales. 
tura exclusivista como el énfasis en Marx no son sino ejemplos de la imposibilidad fáctica de aceptar lo que pretende ser una declaración de principios: «El esquema con que me propongo examinar la historia de la antropología no parte de ninguna toma previa de partido» ${ }^{28}$.

El propósito de Isidoro Moreno en Cultura y modos de producción. Una visión de la antropología desde el materialismo bistórico, no es «realizar una simple descripción del desarrollo de la disciplina, sino analizar ésta críticamente, situando las diversas escuelas y corrientes en su propio contexto y tratando de profundizar en su significación dentro del proceso de construcción histórica de la Antropología» ${ }^{29}$. A diferencia de Llobera, el punto de vista desde el que se juzga al resto de las opciones metodológicas es aquí explícito, lo cual no significa que se den a conocer las razones que hacen preferible la elección del materialismo histórico al resto de las corrientes de investigación. Son numerosos los problemas históricos y epistemológicos que esta obra trata, pero tal vez conviene destacar la tesis que subyace a lo largo de la misma: «La Antropología es hija, no exclusivamente pero sí en gran parte, del colonialismo» ${ }^{30}$. Dicha afirmación, aunque se admita una cierta autonomía que evite «estériles mecanicismos», no pasa de ser un lugar común en el que conviene no estacionarse. En relación con este tema parece evidente que no se pueden dejar a un lado factores tales como la ideología de los antropólogos, el uso de la antropología por la metrópoli, la relación entre antropología y sociedades antiesclavistas, la valoración de la antropología por las administraciones coloniales, etc. ${ }^{31}$. Para

28 J. R. LlobERA, Hacia una historia de las ciencias sociales..., p. 53.

29 I. Moreno, Cultura y modos de producción. Una visión de la antropología desde el materialismo histórico (Madrid: Ed. Nuestra Cultura, 1979) (1978), p. 220. La insistencia en lo crítico de la historia en cuestión o del análisis de ésta parece haberse convertido en norma para censurar lo existente, en lugar de reflexionar sobre ello para señalar sus cualidades; véase, en esta línea, el texto ya citado de E. Ronzón, Antropología y antropologías. Ideas para una historia critica de la antropología española. El siglo XIX.

$30 \quad$ Ibidem, p. 8.

31 Sorprende una postura tan radical en un autor entre cuyos ensayos más conocidos figura «La antropología en Andalucía. Desarrollo histórico y estado actual de las investigaciones», Ethnica, 1 (1971), pp. 107-144. Si algo ha quedado claro tras el auge de obras ya lejanas como la de Gérard LECLERC (Antropología y colonialismo, Madrid: Alberto Corazón, 1973 [1972]), es que la relación entre antropología y colonialismo no es tan fácil de determinar como se había señalado inicialmente. Así se puede advertir en el capítulo dedicado al tema por Adam KUPER (op. cit., pp. 123-147). También es significativa la actitud de LlOBERA, quien ha pasado de defender que «la antropología se desarrolló en relación estrecha, en una situación de casi dependencia con el mundo colonial» (art. cit.[1975], p. 376), a indicar que las correlaciones entre el colonialismo 
ello, la brevedad del libro, al que no se le puede discutir su valentía y utilidad, resulta ser un obstáculo insalvable.

Julio Caro Baroja se ha acercado de nuevo a la historia de la antropología, una disciplina a la que ya dedicara interesantes trabajos con anterioridad, con dos interesantes libros ${ }^{32}$. Si hubiera que destacar una característica de estas dos obras deberíamos mencionar su independencia respecto a polémicas pasadas y presentes sobre historia de la antropología. El autor no discute sobre el origen de la antropología, el papel de Marx en el desarrollo de ésta, el uso del pasado en beneficio del presente o el estudio del pasado por el pasado. Su empeño es, más bien, buscar ideas de carácter antropológico en fragmentos y opúsculos presocráticos:

Al pretender trazar una historia de la Aurora del pensamiento antropológico debe quedar bien claro, desde el principio, que no se trata de hacer una historia de los comienzos de la Antropología como ciencia, sino de las ideas que, aunque se hallen desarrolladas por los antropólogos modernos, considerados como tales, se encuentran ya, más clara o más oscuramente formuladas en las obras (o en los fragmentos y referencias a ellas) de pensadores muy anteriores a la fase en que se crea la Antropología como tal ciencia ${ }^{33}$.

Pero afrontar esta labor obliga al autor a realizar una mezcolanza de ideas biológicas o físicas y de carácter cultural cuyo parecido con las ideas actuales provoca una cita continua de obras y movimientos antropológicos de nuestra época.

La noción que Julio Caro Baroja tiene de la antropología en la antigüedad es directa heredera de su visión de la antropología como una forma de erudición y humanismo, algo que se hace todavía más claro cuando ha de justificar su elección de Kant como origen de Los fundamentos del pen-

y la antropología «no son aceptables como verdaderas explicaciones» (Hacia una bistoria de las ciencias sociales..., p. 55). F. del PINo discutió lo que a inicios de los setenta parecía ser una firme realidad en «Antropología y colonialismo: anotaciones para el caso español», Revista Española de la Opinión Pública, 42 (1975), pp. 145-155, y suya es también la última palabra en este debate, vinculando la antropología no tanto al colonialismo como a la propia psicología del antropólogo que forma parte de minorías religiosas, sociales o ideológicas, dentro de su propio país, y por ello está en condiciones de reconocer mejor que el resto de sus compatriotas, que constituyen la mayoría, las específicas características culturales de otros grupos sociales: «Antropología, colonialismo y minorías culturales», Antropología. Revista de pensamiento antropológico y estudios etnográficos, 1 (1991), pp. 5-26.

32 La aurora del pensamiento antropológico. La antropología en los clásicos griegos y latinos (Madrid: CSIC, 1983) y Los fundamentos del pensamiento antropológico moderno (Madrid: CSIC, 1985).

33 J. CARO BAROJA, op. cit. (1983), p. 7. 
samiento antropológico moderno. Pocos escritores tendrán el valor de reconocer que han comenzado con un autor «porque es el filósofo que desde un punto de vista crítico, limitado, más me ha influido, desde los días de la juventud» ${ }^{34}$. Sin embargo, este libro encierra valiosas sorpresas que debemos valorar: aunque hace un uso abundante de la Historia de la etnología de Lowie, don Julio no duda en salirse del modelo que éste representa para tratar el movimiento folklórico europeo y sus dimensiones, y la antropología criminal. Sólo con un criterio a la vez independiente y comprensivo se pueden incluir estos dos capítulos dentro de una historia de la antropología; un mal entendido cientifismo y el peso de una mirada apegada en exceso al presente, impiden a muchos admitirlos dentro de la misma ${ }^{35}$. Si a esa independencia unimos la ponderación y la sencillez con que se explican las ideas expuestas en Los fundamentos del pensamiento antropológico moderno habremos definido las cualidades de esta obra.

La antología de textos reunida por Joan Bautista Llinares Chover bajo el título de Materiales para la bistoria de la antropología, es un ejemplo perfecto para demostrar que no siempre la cantidad contribuye a una mejor comprensión ${ }^{36}$. Estamos ante una selección de textos de autores tan dispares como Llobera, Meek, Lévi-Strauss y el propio Harris, reunidos con propósitos pedagógicos y con la intención de perfeccionar la obra similar de Palerm. La pretensión no es mala en sí misma, el problema es que el autor mezcla la cita ya comentada de Llobera sobre Marx; recomienda el estudio de Meek - centrado en la Ilustración, no lo olvidemos- para analizar a Lucrecio y al P. Acosta; utiliza el artículo de Lévi-Strauss sobre «Las tres fuentes de la reflexión etnológica», donde se defiende el origen renacentista de la antropología, y lo mezcla con su conferencia «Jean-Jacques Rousseau, fundador de las ciencias del hombre»,

$34 \quad$ Ibidem (1985), p. 19.

35 En -esta tarea el antecedente más interesante tal vez sea el libro de Luis MARISTANY, El gabinete del doctor Lombroso (Delincuencia y fin de siglo en España) (Barcelona: Anagrama, 1973). Miguel Ángel PUIG-SAMPER y Andrés Galera dedican el capítulo IV de su breve libro La Antropología española del siglo XIX (Madrid: CSIC, 1983), a la «antropología criminal», pero su tratamiento parece dejar a un lado el carácter multidisciplinar que la disciplina poseía en el siglo XIX, otorgando cierto predominio a la antropología física.

36 J. B. LLINAREs ChOver, Materiales para la bistoria de la antropología (Valencia: Nau Llibres, 3 vols., 1982, 1983 y 1984). 
sin hacer mención de la contradicción que ambos implican ${ }^{37}$. Finalmente, considera que «nuestro volumen permite una utilización de los fragmentos que en él citamos y de sus presentaciones correspondientes, independiente y complementaria con respecto al libro de Harris» ${ }^{38}$, cuando probablemente los textos que Llinares Chover ha reunido supongan el mejor mensaje ecléctico contra una obra de escuela como la de Harris. En cualquier caso, si lo que justifica el esfuerzo realizado es la finalidad pedagógica del texto, no podemos dejar de reconocer las insuficiencias que padece esta antología: la bibliografía general que se incluye en el segundo volumen no reproduce mucho de lo bueno que existe sobre historia de la antropología; algunas referencias a autores y textos se dan sin su correspondiente traducción al castellano, mucho más accesible generalmente, y, en ocasiones, la mezcla de temas que se pretende mostrar en un autor, resulta poco más que simbólica. En definitiva, con esta antología se tiene la sensación de que una edición de textos de más de 1.000 páginas dedicadas a la historia de la antropología no han sido aprovechadas como sería de desear.

La obra colectiva editada bajo la dirección de Ángel Aguirre Baztán pretende elaborar una historia de la antropología española a partir de la historia de las distintas regiones que la componen ${ }^{39}$. Es una obra amplia, documentada y con abundante bibliografía, aunque como en toda obra relizada por varios autores, cada aportación posee sus propias características. La parte inicial de la obra es un buen resumen de su director hecho a partir de los artículos regionales. También es obra de Aguirre el artículo dedicado al País Vasco y Navarra, donde, tal vez por la escasez de historias locales de la antropología, se centra en las figuras más conocidas (Aranzadi, Barandiarán y, menos, Caro Baroja). Finalmente, también se debe a Aguirre Baztán un amplio artículo sobre Claudio Esteva Fabregat, por cuya obra y labor manifiesta su admiración; de él podemos decir que es exhaustivo, no tanto por la bibliografía del autor citada, que se encuentra en la Autobiografía de Esteva ${ }^{40}$, como por el análisis donde se enmarca.

37 C. LÉVI-Strauss, «Las tres fuentes de la reflexión etnológica», J. R. Llobera (ed.), La antropología como ciencia (Barcelona: Anagrama, 1975), pp. 15-23 (1960); «Jean Jacques Rousseau, fundador de las ciencias del hombre», C. LÉVI-STRAUSs, Antropología estructural. Mito-Sociedad-Humanidades (México: Siglo XXI, 1979), pp. 37-45 (1962).

38 J. B. LlinARES ChOver, op. cit., III, p. 12.

39 A. Aguirre Baztán (ed.), La antropología cultural en España. Un siglo de Antropología (Barcelona: P.P.U., 1986).

40 C. Esteva Fabregat, «Autobiografía intelectual», Antbropos, 10 (marzo de 1982), pp. 4-25. 
Manuel Mandianes Castro es el autor del estudio sobre Galicia. Su insistencia en lo arbitrario de la periodización de la historia que narra y la falta de fechas, así como la ausencia de justificación del paso de un período a otro, sugieren que todavía quedan por resolver bastantes problemas en la historia de la antropología gallega. Luis V. Elías Pastor se ocupa de la etnografía de La Rioja y José Luis Acín Fanlo de Aragón. En este segundo caso se echa de menos una mayor atención a la obra de Joaquín Costa, sobre la que existe bibliografía. Asimismo, puesto que no sobran precisamente los trabajos de campo, parece un descuido la falta de mención del libro de Carmelo Lisón sobre Belmonte de los Caballeros ${ }^{41}$. De Cataluña se ocupa Josefina Romá Riu. La autora asume en su pleno sentido el título de su artículo «Etnografía y folklore en Cataluña», y en contra del criterio amplio utilizado por el resto de los colaboradores de esta obra, no trata la etapa posterior a la guerra civil, «retomada por los antropólogos». Josefina Romá se ha ocupado también de la obra de Julio Caro Baroja, si bien, a diferencia del artículo dedicado por Aguirre a Claudio Esteva, el estudio de sus obras ha dado paso en esta ocasión al estudio de su persona.

Julián San Valero Aparisi proporciona abundante bibliografía de los trabajos de sus alumnos en su estudio de la etnografía y el folklore de Valencia y Murcia. El autor no parece ocuparse en exceso de las obras de antropología sobre estas regiones. Este es el caso de Sebastián Trias Mercant al tratar de Mallorca: descuida los trabajos de campo de los últimos años en aquella zona. Interesantes son, sobre todo, las revistas y departamentos universitarios que relaciona Luis Calvo Calvo en la región castellana. Esta misma labor se ve ampliada al final del libro para todas las regiones. La aportación de Salvador Rodríguez Becerra sobre Andalucía es uno de los artículos más interesantes y completos de esta obra. Tanto la bibliografía que proporciona al final del mismo, como la historia que narra, son ejemplos de una tarea bien hecha. Los comentarios que utiliza para explicar las dificultades burocráticas de la antropología andaluza constituyen buenos datos de un conocedor de la cuestión «desde dentro». Javier Marcos Arévalo aporta también un completo estudio sobre Extremadura. Consigue los objetivos que se había propuesto: apuntar fuentes documentales, producciones etnológicas y las etapas en que se enmarcan éstas. Por último, Isabel Badillo

41 C. Lisón Tolosana, Belmonte de los Caballeros. A Sociological study of a Spanish Town (Oxford University Press, 1966). 
León trata de la etnografía y el folklore de la región canaria en un trabajo que debe mucho a la conocida obra de José Pérez Vidal ${ }^{42}$.

En resumen, estamos ante un libro de los más completos que se han hecho en España sobre el tema, pero resulta muy desigual. Frente a excelentes historias se incluyen semi-relatos; junto a documentadas bibliografías aparecen lagunas incomprensibles. La misma «bibliografía en torno a la historia de la antropología cultural en España», que se incluye a modo de síntesis, resulta bastante incompleta. Faltan regiones por estudiar y el concepto de antropología es relativo, a veces se incluye mucha literatura y en ocasiones se restringe en exceso. Los comienzos de las historias tampoco son uniformes: romanos, siglo XV, XVIII y XIX, se alternan según el gusto del autor.

La conclusión que podemos extraer tras comentar estas obras es que la historia de la antropología española ha avanzado considerablemente, pero aún tiene por delante un amplio sendero. Están por determinarse cuáles han sido las contribuciones de determinados períodos: Renacimiento, Ilustración y Romanticismo. Hay que seguir profundizando en la segunda mitad del siglo XIX, y queda por hacer un balance global de este siglo. Si aceptamos que el antropólogo es desde un punto de vista individual un marginado, no podemos dejar de lado, además, la figura tan tradicional en el ámbito español del transterrado ${ }^{43}$; una historia de la antropología española debe incluir a los numerosos etnólogos españoles que han ejercido su actividad fuera de nuestro país. Asimismo, varias figuras de primera magnitud parecen exigir estudios específicos ${ }^{44}$. Respecto a las historias globales, los textos de autores españoles suelen servirse de los de sus colegas extranjeros, pero presentan sus mismos problemas: el dilema en torno a la aportación de Marx, la defensa explícita o implícita de la propia opción metodológica, la indefinición o el dogmatismo a la hora de fijar el origen de la disciplina, etc. Ahora podemos apreciar, incluso con las escasas muestras sobre las que hemos establecido la comparación, que las dos décadas de continuidad en

42 J. Pérez VIDAl, Los estudios del folklore canario 1880-1980 (Madrid: I.C.E.F., 1982). Sobre los estudios de la antropología canaria: A. GALVÁN Tudela, Islas Canarias. Una aproximación antropológica (Barcelona: Cuadernos de Antropología-Anthropos, 1987).

43 Hay varias aproximaciones al tema: F. del PINO, «Antropólogos en el exilio», J. L. ABellán (dir.), El exilio español de 1939 (Madrid: Taurus, 1978), vol. 6, pp. 13155; J. A. Ortega Medina, «Antropología», El exilio español en México. 1939-1982 (México: Salvat-F.C.E.), pp. 309-361.

44 Existen numerosos artículos, pero faltan obras definitivas, aunque se puede señalar alguna: C. ORTIZ GARCfa es autora de Luis de Hoyos Sáinz y la antropología española (Madrid: CSIC, 1987), autor al que ha dedicado, además, su tesis doctoral y varios artículos. 
historia de la antropología admiten una división. Si queremos ser exactos debemos reconocer que en ese período se dan cita dos formas distintas de hacer historia de la antropología. Inicialmente la historia de la antropología en España se configuró como la historia de la antropología española; se trataba de demostrar el arraigo de esta disciplina en nuestro país, pero no cabía duda alguna de su minoría de edad respecto a las grandes antropologías. De ahí que en el terreno de la historia de la antropología internacional no hubiera posibilidad alguna de competir: debíamos hacer uso de los manuales de historia que venían de fuera. La fragmentación posterior de las historias nacionales en historias regionales, anunciada con bastante antelación en las aportaciones de algunos autores, guarda estrecha relación, como ya hemos dicho, con la configuración autonómica de nuestro país, pero sigue dejando en manos extrañas la explicación de la gran teoría. Sólo con posterioridad a las historias nacionales, comenzaron a aparecer obras de autores españoles sobre historia de la antropología no estrictamente local. De su validez, así como de la necesidad de uno y otro tipo de historia, nadie puede tener duda alguna; el problema es que ni unos ni otros pueden sustituir a las historias de la antropología traducidas. Las historias de la antropología española porque dejan fuera de sí el desarrollo de la parte más importante de la teoría antropológica; sería absurdo intentar explicar una historia de la ciencias sociales, por muy cercana que nos fuera, en la que estuvieran ausentes Marx, Weber o Durkheim. Las historias de la antropología globales hechas por españoles tampoco pueden sustituirlas porque, nos guste o no, las importadas son comparativamente superiores.

Si la historia de la antropología debe contribuir al desarrollo de la teoría antropológica aclarando las características de ésta en cada época, es evidente que no podemos renunciar a escapar del laberinto. Pero tal vez la única salida sea poner en conexión las historias locales y las internacionales. Los manuales franceses, ingleses y norteamericanos son, a la par, nativos y cosmopolitas; sus autores estudian la propia tradición a la vez que investigan sobre la teoría antropológica. Ese es el hábito de trabajo que puede permitirnos, de una parte, desarrollar la historia de la antropología española, $y$, de otra, convertir en adultos a los historiadores de la antropología españoles. La opción no es, por tanto, historia local o historia internacional, la elección hay que realizarla entre una historia de la antropología sin futuro y una historia de la antropología que pretenda decir algo.

Francisco CASTilla URbano 
La historia de la antropología española ha experimentado un gran impulso en los últimos veinte años, pero la formación de los antropólogos españoles sigue dependiendo de textos históricos hechos por extranjeros. La unificación de las dos líneas de investigación que se aprecian dentro de la historiografía de la antropología en España, la nacional o regional y la general, puede permitir la sustitución de las obras foráneas por las que escriban los autores nativos.

The importance of the Spanish Anthropological History has increased considerably during the last twenty years, but the training of the Spanish anthropologists still depends on historical texts written by foreign scholars. By joining together the two main research tendencies which can be considered within Spanish Anthropology's Historiography - that means the national or the regional, and the general one-, it's feasible to substitute foreign works by those written by native authors. 